\title{
The Locked-in Syndrome: A Review and Presentation of Two Chronic Cases
}

\author{
P. Dollfus, MD, ${ }^{1}$ P. L. Milos, MD, ${ }^{(\dagger) 1}$ A. Chapuis, MD,${ }^{1}$ P. Real, MD, ${ }^{2}$ \\ M. Orenstein, $M D^{2}$ J. W. Soutter, $M^{2}$ \\ ${ }^{1}$ Centre de Readaptation, 57 rue Albert Camus, 68093 Mulhouse Cedex, France, \\ ${ }^{2}$ Centre Hospitalier de Mulhouse, B.P. 1070, 68051 Mulhouse Cedex, France.
}

\section{Summary}

The locked-in syndrome (LIS) is a state of an upper motor neurone quadriplegia involving the cranial nerve pairs with usually a lateral gaze palsy, paralytic mutism, full consciousness and awareness by the patient of his environment. A historical presentation of the LIS is given as well as a short description of the clinicoanatomic lesion causing LIS. The usual cause is vascular and corresponds to a pontine infarction due to an obstruction of the basilar artery but other lesions in the brainstem can also be the cause. Non-vascular aetiologies, especially traumatic, are reviewed. The use of electroencephalography (EEG), brain auditory evoked potentials (BAEP) and somesthesic evoked potentials (SEP) are discussed as well as the use in the acute stage of computed tomography (CT), angiography, and magnetic resonance imagery $(M R I)$. The last method may show well delineated ischaemic lesions some time after the event. The communication disability is probably the most difficult to overcome. Two cases of LIS are presented.

Key words: Tetraplegia; Locked-in Syndrome; Pontine Infarction; Communication Disability.

The locked-in syndrome (LIS), a term which has been finally adopted since the publication by Plum and Posner in 1966, was, in fact, described more than 100 years ago, by Alexandre Dumas (father) who depicted in 1846 quite accurately in his novel 'The Count of Monte Cristo', Monsieur Noirtier as a 'corpse with living eyes'. Mr Noirtier had been in this state for more than 6 years and could only communicate by blinking his eyes.

In 1868, a similar situation occurred in the novel Therèse Raquin written by Emile Zola. The mother of Thérèse presented a progressive form of LIS after very well described prodromes. To communicate '... she managed to use her eyes as a hand, as a mouth, to ask and thank'. Matters were made even worse when she found out, through the murderers themselves, that her son Camille had been murdered by her daughter-in-law, Thérèse, and her lover, Laurent. 
In 1876, Darolles, a French physician, was the first to give a very accurate clinical and pathological report on what we would today describe as a 'total' case of LIS lasting only for a few hours before death took its toll. His patient, a woman in her late $30 \mathrm{~s}$, presented a status where she was unable to speak but consciousness was in no way impaired. She presented a progressive supranuclear brainstem quadriplegia with decerebrate posturing, inability to speak and to swallow. Communication was then established thanks to the vertical movements of her eyes even though lateral gaze was paralysed. The neuropathologic examination showed a unilateral pontine infarct the size of a 'hazelnut', due to a total occlusion of the basilar artery by thrombosis.

Until 1966, when it was given its actual term by Plum and Posner, the syndrome has been described as 'ponto pseudo-coma', 'ventral pontine syndrome', 'de-efferented state', 'cerebromedullospinal disconnection', 'pontine disconnection syndrome', 'ventral brainstem syndrome' a 'state resembling akinetic mutism in a basilar artery occlusion', and even 'Monte Cristo's syndrome'. Filiminov has also in the Russian medical literature described this syndrome before it acquired its actual denomination (Erokhina et al., 1986). It has been reviewed in recent years by Virgile (1984), Patterson and Grabois (1985), Haig et al. (1986) and Pearce (1987).

The LIS can be described as a supranuclear quadriplegia, with at first decerebrate posturing which in most cases, is associated with a lateral conjugate gaze palsy, and the preservation of vertical eye movements combined with synergic elevation of the upper eyelids when looking upwards. At least, in pontine lesions, the convergence movement system and stereopsis are intact as the motor centre is situated in the mesencephalon. One of its cardinal features is the preservation by the patient of consciousness and awareness of his environment and himself which allows the syndrome to be distinguished from that of 'akinetic mutism' which is clinically different and due to other pathological processes (Plum and Posner, 1966; Delcour et al., 1982; Nemeth et al., 1986). The paralytic inability to speak has been named by most authors as 'anarthria' or 'mutism', terms which are open to discussion. The anatomical lesions corresonding to the LIS clinical signs have been correlated by several neuropathological studies in the literature, mainly in vascular, haemorrhagic or tumoural lesions. Nevertheless, in rapidly evolving and extensive ischaemic lesions, it is difficult for the pathologist to individualise the specific responsible brainstem lesion (Reznik, 1983). The most predominant cause seems to be the occlusion of the vertebral basilar artery, usually predominating in its rostral or middle segments, clinically preceded or not by vertebral basilar insufficiency prodromes.

Other cases of LIS have been described where the lesion was situated in the central part of the pons or in the mesencephalic region, mainly at the level of the cerebral peduncles (Girard et al., 1962; Karp and Hurtig, 1974; Dehaine and Martin, 1976; Meienberg et al., 1979; Dehaine and Dom, 1982). Other aetiologies are more difficult to correlate and will be discussed later.

In most cases, the clinical signs remain easy to comprehend, especially in a purely ventral pontine infarction as the pyramidal tract fibres are interrupted as they traverse the ventral part of the pons leading to a loss of motor control below. The interruption of the corticobulbar fibres, which peel off at different levels to reach (crossed or uncrossed) the motor nuclei of the cranial nerves 
will specifically, at the pontine level, affect the 'final common pathway of the oculomotor laterality' (Pierrot-Deseilligny, 1985). This will cause a supranuclear paralysis of the VIth (abducens) cranial nerve pair. Should the lesion extend, unilaterally or bilaterally, towards the tegmentum, beyond the boundary of the medial lemnisci and, in some cases, laterally, (Nordgren et al., 1971; Hawkes, 1974; Dehaine and Martin, 1976), matters become perhaps more difficult to correlate.

Today we understand better the role of the reticular formation (RF), so important for the 'activation' of the brain for behavioural arousal and the control of levels of awareness (Kelly, 1985). The pontine RF neurones do play an important role in the modulation of muscle tone and have, as in other parts of the brainstem, many other complex afferent and efferent functions as the RF neurones are grouped specifically according to their chemical messengers.

Concerning the horizontal ocular movements, the neurones of the RF, in the pontine gaze centre, are heavily involved in the programming of the eye movements. These RF neurones are situated in the paramedian pontine reticular formation (PPRF) and discharge in relation to the horizontal eye movements (Gouras, 1985). In incomplete or unilateral lesions, massive or lacunar damages can extend, involving the motor neurones of the VIth cranial pair (Dehaine et al., 1984), thus giving an added unilateral nuclear palsy. Extensive lesions, or those close to the tegmentum, can also affect the medial longitudinal fasciculi, resulting in a complex internuclear 'one and a half syndrome' (Fisher, 1967) or exotropia which has been described in LIS (Masson et al., 1978; Delpuech et al., 1981; Prier et al., 1982; Bogousslavsky et al., 1984). The phenomenon of 'ocular bobbing' has also been described in the literature by Fisher in 1964 as '... the eyes intermittently dip briskly downwards through an arc of a few millimetres and then return to the primary position in a kind of bobbing action'. For Fisher this could represent 'normal roving movements of the eyes in which the lateral component is in abeyance leaving the vertical excursion in evidence'. The possibility of 'ocular bobbing' being a voluntary movement action has been debated. Skewing is not an uncommon phenomenon and so is the ocular instability which can be a great handicap.

As the lesion can also extend laterally involving the fibres of the lateral lemnisci, their function and integrity can be explored by sophisticated methods, such as brainstem auditory evoked potentials (BAEP). The BAEPs can show (on the same side of the lesion) a certain degree of latency and diminished amplitudes of waves IV and V (Stockard et al., 1976; Gilroy et al., 1977; Seales et al., 1981). This investigation method using BAEPs can be useful not only to localise but, eventually, to follow the evolution of the lesion (Seales et al., 1981). The alterations of the median nerve evoked somesthetic potentials can also be useful in evaluating the extent of a medial lemniscus lesion. It is interesting to note that SEPs evoked from the lower limbs are conveyed more laterally within the medial lemniscus (Noel and Desmedt, 1975) but also that, at least, in the chronic phase, sacral SEPs evoked from the dorsal nerve of the penis can be normal or close at normal (at least in the 2 cases presented later).

Electroencephalography (EEG) has been used by many authors to ascertain the cortical integrity in such patients (Bauer et al., 1979) but also to study the 
sleep-waking patterns (Markand and Dyken, 1976; Robert, 1980; Tamura et al., 1983). These can range from normal to severely limited non-rapid eye movements (non-REM) and to no rapid eye movements (REM) activity. The major finding is perhaps that of hyposomnia and in some instances patients have reported that they did not sleep at all, indeed for several months. Other authors (Patterson and Grabois, 1985) report mainly a disorganised pattern as the major common finding. Non-REM sleep can be absent or reduced. The EEG can therefore be very useful to detect sleep abnormalities which could be correlated with a lesion of the median raphe nuclei of the reticular formation in the pons.

In cases of vascular origin, angiography and, by preference, digital substraction still remains the basic examination to try and visualise the exact location and the extent of the basilar artery obstruction. However computed tomography (CT), after injection of contrast, could be of immediate therapeutic interest if performed less than 6 hours after onset and will be discussed later.

CT can also be useful to diagnose a haemorrhage or a space occupying lesion such as an epidural haematoma in traumatic cases, vascular malformations, a tumour, an abscess, a tentorial herniation or even a central pontine myelinolysis. The recent development of magnetic resonance imagery (MRI), has become (when available) even in the acute phase, another useful tool.

The aetiologies of a non-vascular LIS are very widespread. These have been enumerated in the extensive review by Patterson and Grabois in 1985. They range from traumatic, infectious, toxic, metabolic, (alcohol and heroin abuse) and include non-CNS causes such as infectious polyneuritis. Among the most frequent non-vascular causes is that of trauma. Feldman in 1971 was one of the first to report such a case. Keane in 1986 reported 10 cases and distinguished between a direct injury to brainstem and a secondary infarction after 6-48 hours delay due to a vertebral artery dissection leading to a formation of a thrombosis occluding the basilar artery. Although most of the clinical improvements have been reported as 'slight' to 'moderate', nevertheless some complete recoveries have been reported (also in other aetiologies), but they are rare. LIS of traumatic origin has also been described after chiropractic manipulations as here the vertebral arteries can be particularly vulnerable to hyperextension and rotational manoeuvres between the occipital bone and the atlas.

Clinical varieties of LIS have been described (Bauer et al., 1979), as the LIS has different aetiologies as well as clinical and pathological variations. These authors have distinguished between a total LIS in which there is a complete immobility except for the vertical eye movements: the diagnosis resting mainly on the EEG findings which confirm minor or undisturbed cortical functions. An incomplete LIS is the case where there is some, even minimal, additional motor function including some ocular laterality movements. They also described the transient LIS evolving towards recovery, partial or complete (McCusker et al., 1982). One could add the chronic LIS where minimal or no recovery has been seen after 1 year. Some patients have been reported as still living after periods of more than 12 years. This has been extensively reviewed by Patterson and Grabois (1985), and Haig et al. (1986).

Survival has been linked, in the literature, with the age group, the youngest being in the traumatic group (mean age: 32 years) (Patterson and Grabois, 
1985). It has also been reported in children (Golden et al., 1976) (Kotagal et al., 1984). Mortality is the highest in the vascular group (67\%) compared with the non-vascular group $(41 \%)$. Full recovery is a rare event in the vascular group compared with the non-vascular group as reported by different authors. Two cases of LIS, now in the chronic stage, follow:

\section{Case 1}

A 28-year-old man, with no past significant medical history. On 12 February 1986 (Day 1) he was involved in a car accident, apparently with an initial loss of consciousness. On arrival in the emergency ward of the Mulhouse hospital, his consciousness appeared to be intact but he presented in severe hypovolaemic shock due to fractures of the right femur, the right humerus, a severe thoracic contusion associated with a haemopneumothorax and a scalp wound. Although the patient seemed agitated and at times confused, the neurological examination was normal. The haemopneumothorax was drained, the fractures reduced clinically under general anaesthesia, and later on, osteosynthesised. He was put onto a controlled ventilation.

On the second day (Day 2), the neurological status deteriorated: absence of verbal contact, noxious stimulations inducing decerebrate posturing and a double sided Babinski. The pupillary reflexes were present and equal. CT showed the presence of disseminated ischaemic lesions at the level of the pons, the cerebellar vermis, the right thalamus and the internal capsule. Vertebral angiography showed a thrombosis of the left vertebral artery probably due to a fracture of the VIth cervical transverse process, confirmed by a vertebral CT (Fig. 1). This led to the suspicion of a vertebral artery dissection causing a thrombosis extending upwards to the basilar artery. The electroencephalography (EEG) showed a state of somnolence, was reactive, and showed no cortical lesions.

On Day 3, a new CT confirmed these disseminated lesions. The absence of spontaneous motor activity of the four limbs was noted. On Day 5, eye opening under stimulation was recorded. On Day 7, the patient could communicate by opening and closing his eyelids. Vertical gaze was present. No lateral eye movement could be achieved. The neurological examination showed a total upper motor neurone quadriplegia involving

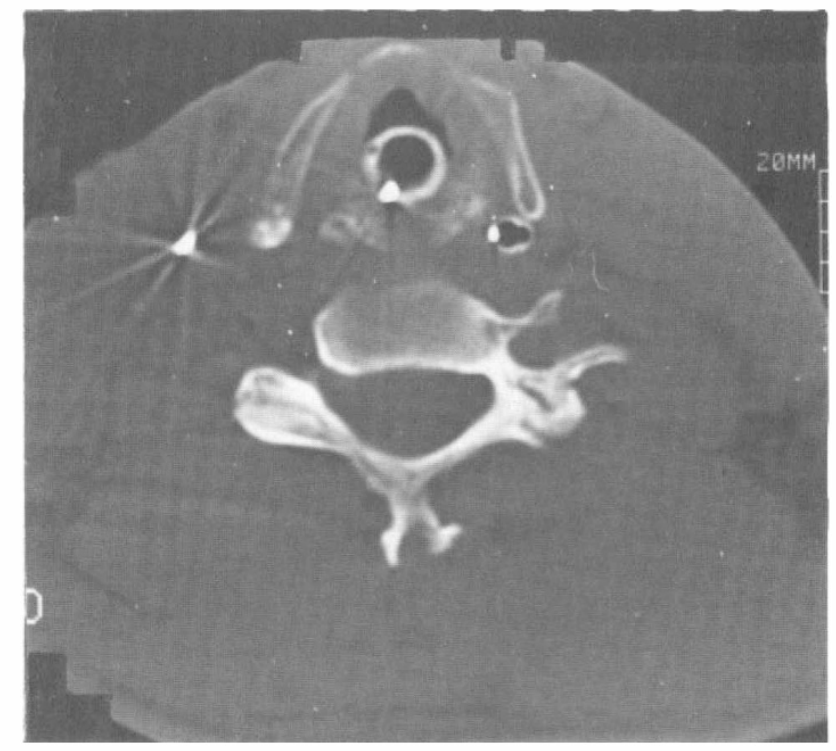

Figure 1 CT scan at the level of C6 showing a fracture of the left transverse process. 
cranial nerve pairs extending from the level of the Vth cranial nerve (motor) downwards. The patient could not open his mouth because of trismus due to masseteric hypertonia. Sensation seemed to be intact on both sides for all modalities. This was confirmed by repeated examinations which were hindered by the difficulty in communication. The diagnosis of LIS seemed to be confirmed. The staff and the family were informed about the communication problems and everybody had to adapt to this quite new situation which will be discussed later.

Naso-endotracheal intubation was replaced by a tracheostomy on Day 14. The indwelling catheter was removed and replaced by a condom urinal, micturition being assessed as satisfactory. The patient was weaned from artificial ventilation once it was found that he had spontaneous eupneic respiration confirming the functional disconnection between the medullary centres from higher brainstem control. Unfortunately it has remained the same since, and the patient still cannot modulate his respiratory rhythm.

Slight, though very inconsistent, voluntary extension and rotation movement of the head towards the right was noted in the fourth week. At that time, there was a partial return of horizontal eye movements towards the right but these were both badly controlled and slow. Eye convergence was thought to be normal throughout. Voluntary swallowing was impaired and remains so in 1988. Automatic deglutition remained possible for fluids and soft food but often led to a 'false route' thus preventing the withdrawal of the tracheotomy tube for safety reasons.

Six weeks after the accident, magnetic resonance imaging (MRI) was performed in Freiburg, Germany, confirming the presence of the ischaemic lesions seen in the previous CT. The pontine lesion was reconfirmed by further CT showing a poorly defined hypodensity in the pontine region.

Soon after admission in the Rehabilitation Centre of Mulhouse, $2 \frac{1}{2}$ months after his accident, the velopalatine rhythmic myoclonias which had been noticed before extended to the right facial muscles and to a lesser degree to the right neck, shoulder muscles and distally to the fingers. Coughing is frequent, probably due to the presence of the tracheotomy tube and occurs as a rather explosive movement accompanied by a reflex flexion movement of the forearms and lower limbs. So is laughing, to a lesser degree, which appears, for good reasons, rather abruptly and produces the same reactive movements.

At the end of his stay in the intensive care unit, some voluntary flexion of the forearms appeared but this weak muscular performance varies enormously during the day and from day to day and is hindered by an extensor muscular hypertonic resistance which is also extremely variable. The latest SEPs (February 1988) show a return of a low voltage $\mathrm{N} 2 \mathrm{O}$ wave on the left but not on the right. Brainstem auditory evoked potentials (BAEP) have consistently shown alterations suggestive of a pontine lesion. The latest MRI performed in the Department of Radiology of the University Hospital of Hautepierre in Strasbourg (Professor J. Tongio), in September 1987, showed a well delineated hyposignal in the upper part of the pons just below the superior cerebellar peduncle and close to the upper part of the fourth ventricle (Fig. 2).

Feeding by a nasogastric tube remained a problem. Finally, 14 months after his admission, a feeding gastrostomy was performed. Nutrition has been possible with ordinary mixed food through the tube since that time.

Psychologically, the patient needed positive support from the start from all the staff and his family, particularly from his wife. His intellectual functions are normal and he is fully co-operative although at times he appears to be over-euphoric.

Communication has been the main problem. The use of communication devices has been hindered by a lack of adequate control sites. At first, attempts were made at the use of an electrical communication board, control being the extensor movements of the neck. This was both unreliable and tiring. In November 1987, thanks to co-operation of the French National Research Council in Marseille, an electronic computerised system was established using as a control an infra-red signal with the generator being fixed to the right rim of his eyeglasses. The signal is interrupted by the elevation of his eyebrow. A new, more flexible, computerised program has been established, thanks to the collaboration of the Institute of Polytechnic Research of Mulhouse. The Swiss environmental control 'James' has also been tried with some success using the lateral movement of his 


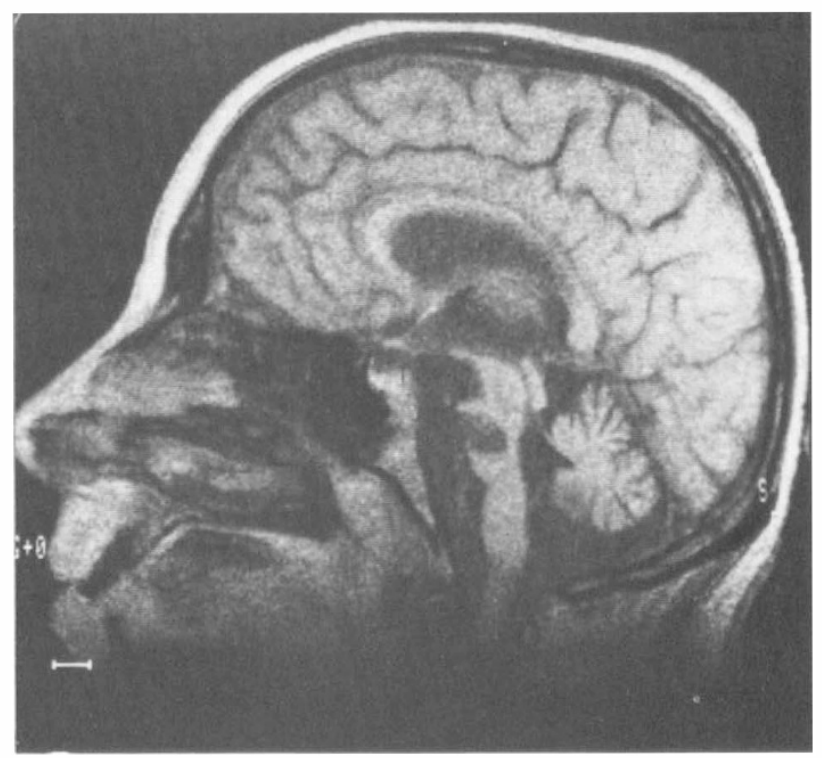

Figure 2 Mid-saggital MRI slice showing the hyposignal in the upper part of the pons.

head as a control. Recently some usable voluntary masseteric activity has been investigated as a possible control. The patient is due to return home shortly.

\section{Case 2}

A 42-year-old man, overweight with a known hyperlipidemia, presented on 7 February 1987 (Day 1) vertebrobasilar insufficiency prodromes: vertigo, nausea, low occipital cephalalgia, rapidly evolving towards a deep coma on the same day. On admission in the intensive care ward in the University Hospital of Besançon, the examination showed a lower limb hypertonia, a tight myosis, normal pupillary reactions and no marked neck stiffness. The attention was immediately drawn by conjugate ocular bobbing. The CT appeared normal. An injection of contrast was then performed showing (1) at the level of the foramen magnum a good visualisation of the vertebral arteries (Fig. 3); (2) at the level of the pons the lumen of the basilar artery was very small and of low density (Fig. 4) compared (3) with a normal visualisation of the arteries at the level of the Circle of Willis (Fig. 5). Digital substraction vertebral angiography was performed showing a thrombosis of the basilar artery mainly in its distal part. The patient was immediately treated with therapeutic vasodilators and heparin. On Day 5 a tracheostomy was performed. On Day 6 a 'total' LIS was diagnosed. On Day 7 a CT showed a hypodensity at the level of the pons. On the same day severe septic shock was diagnosed and was treated with appropriate antibiotics. The EEG was normal throughout the acute phase and remains so in 1988 .

The patient was transferred to us on June 1987, presenting what one would call a 'total' LIS with an upper motor neurone quadriplegia, no horizontal gaze, normal convergence, vertical eye movements and blinking. At times a bobbing-like movement of the eyes is still noticed.

The indwelling catheter was replaced by a condom collector as micturition appeared normal. Sensation seems normal in all its modalities but is still difficult to assess.

Unfortunately a sacral sore appeared during the intensive care phase but has now healed. 


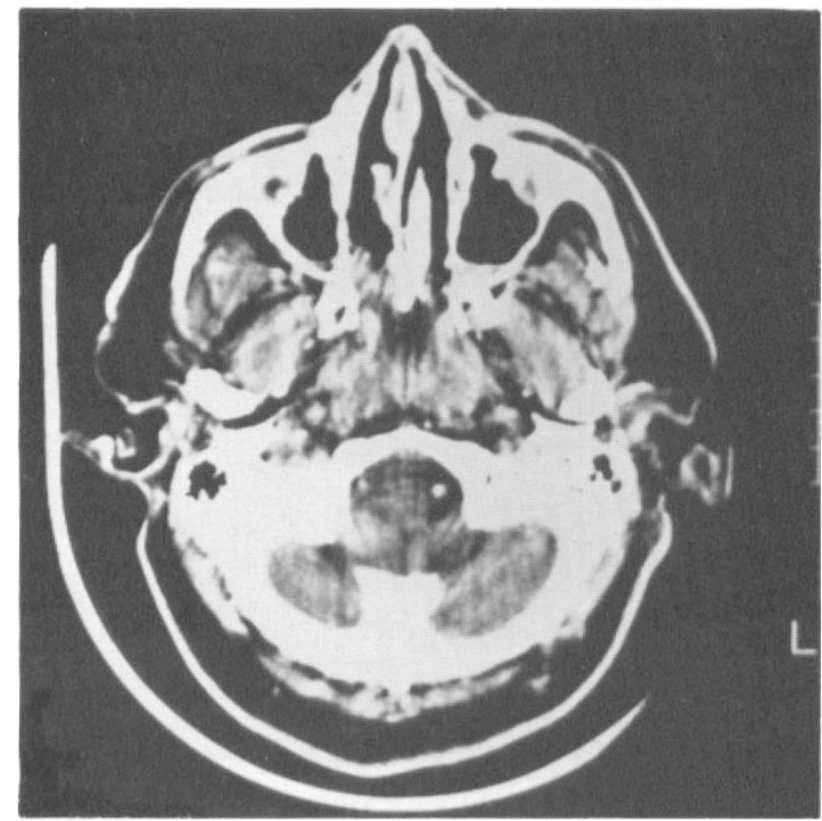

Figure 3 Post-contrast CT scan at the level of the foramen magnum: good filling of the vertebral arteries.

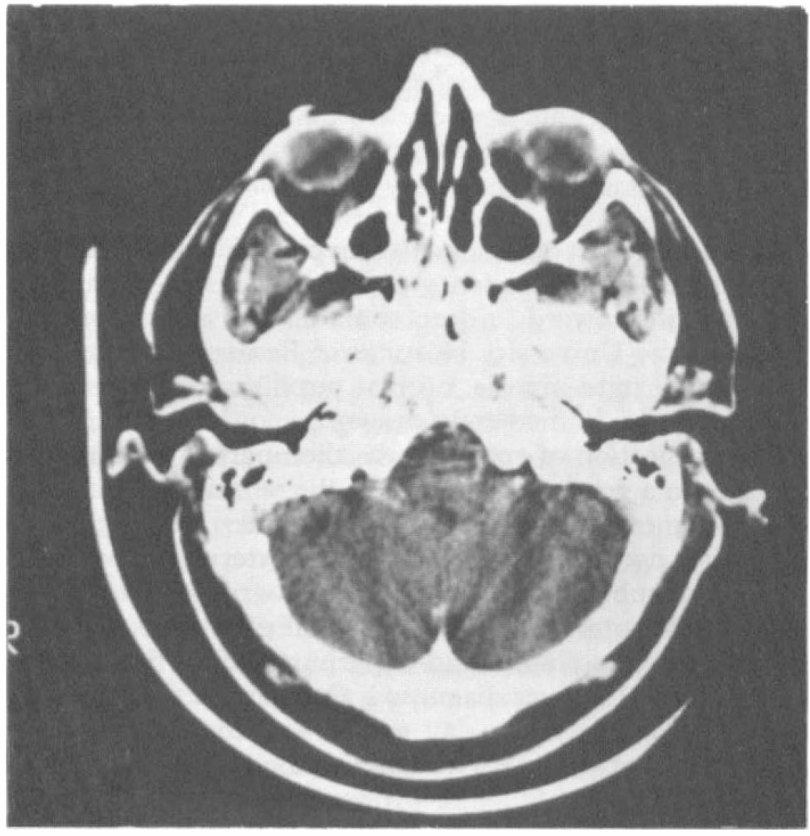

Figure 4 Same CT scan at the level of the pons: very poor filling of the basilar atery.

Median nerve SEPs have shown that the P14 waves originating from the lower part of the pons were present on both sides but waves P18-P20 were abolished.

In September 1987, as for the first case, a MRI was performed in Strasbourg and showed a large hyposignal area in the pontine region extending towards the aqueduct. 


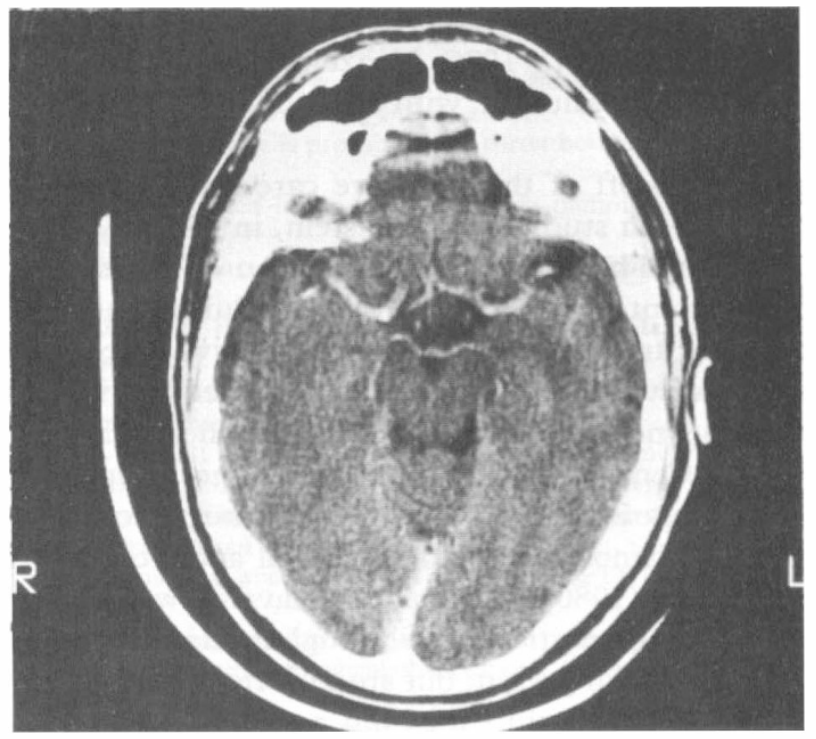

Figure 5 Same CT scan at the level of the circle of Willis, showing a normal aspect.

Communication, in this case, is far more difficult. This is not only due to the consequences of the extent of the lesion but also to the fact that this patient has a totally different personality compared to the first case. His psychosocial background has been traumatic since childhood. His wife has had great difficulties in understanding the situation. There are economic problems and concern has been manifested by the patient himself. Communication difficulties have been experienced by the staff, including the speech therapist and the psychotherapist. It is only recently that the patient, in spite of being very depressed, has shown a better collaboration although very often there are depressive reactions manifested by involuntary movements of crying. The patient is very disturbed by his ocular instability which hinders his vision of medium and even large size letters on a communicating board.

\section{Discussion}

Both of these patients have shown a LIS of vascular origin. The first was due to a possible post-traumatic vertebral artery dissection leading to a thrombosis of the basilar artery. The second case was caused by a basilar artery thrombosis due to an atherosclerotic process.

It is interesting to note that the sacral SEPs evoked by stimulation of the dorsal nerve of the penis are normal in the first case but slightly altered in the second case. This could possibly relate to the lateral somatotopy of the sacral fibres within the median lemniscus.

The physiological and psychological backgrounds are very different in the two cases as well as a relative difference in the age group.

The first case could be categorised as a 'chronic-incomplete LIS', the second as a 'chronic total ILIS'.

Questions still remain concerning the initial therapy. Aggressive anticoagulation and fibrinolytic therapy could not have been used in the first case. In the second case, however, rapid aggressive anticoagulation and vasodilatator ther- 
apy was used. Today the use of fibrinolytic agents should be advocated (Popova et al., 1986; Courtheoux et al., 1986; Henze et al., 1987) in the event of the diagnosis of basilar artery occlusion, with or without prodromes, is made within 6 hours of its occurrence.

The reaction of the staff of the intensive care unit of Mulhouse was very interesting. This has been studied by Orenstein, in 1987. Little has been published on this subject. The psychological reaction of the staff to LIS varied from treating the patient in a maternal way (as during the awakening phase after a head injury) or treating the patient as a passive object, questions being asked expecting no answer. It seemed that the general attitude was that of a 'too terrible to be true' negation of the LIS phenomenon. This was experienced at the Rehabilitation Centre but only for a short time. It appears that the best communication exchange is that achieved between the person and his spouse.

Involuntary motor phenomena are not unusual and were first reviewed and discussed by Bauer et al. (1980). Both patients have shown these types of movements (yawning, laughing, mastication) although in the second case 'pathologic' movements of crying are still present but are they really involuntary?

Return to home is quite possible for both patients. It has been achieved for short periods on frequent occasions and the second case has now been discharged. The primary care givers are the spouses who have gained a good knowledge concerning the complications that can occur.

\section{Conclusion}

In spite of its apparently rare occurrence, LIS was diagnosed rapidly in both patients. They have now reached a chronic stage, and demonstrate that with proper initial intensive care and rehabilitation, preferably within a spinal cord lesion unit, such patients can survive in relative comfort in spite of this most awful disability. Examples from throughout the literature have shown that a rather limited degree of re-integration is possible. Communication remains a very difficult problem. We depend on the possibilities offered to us, in the present and the future, by the progress of modern sophisticated communication technology. In no manner should any of these patients be condemned to a 'conscious hell' (Pearce, 1987).

\section{Acknowledgements}

We wish to acknowledge the help of the Department of Neuroradiology of the University Hospital of Besançon (Professor Bonneville) and Dr Bourrin, Neurologist, Chief Consultant, at the Hospital of Mulhouse. We are grateful to the Foundation of France for a grant allowing further research in the problem of communication with these patients.

\section{References}

BaUer G, Gerstenbrand F, RUMPL R 1979 Varieties of the locked-in syndrome. Fournal of Neurology 221:77-91.

BaUer G, Gerstenbrand F, Hengl R 1980 Involuntary motor phenomena in the locked-in syndrome. Fournal of Neurology 223:191-198.

Bogousslavsky J, Miklossy J, Regli F, et al. 1984 One-and-a-half syndrome in ischaemic 
locked-in state: a clinicopathological study. Fournal of Neurology, Neurosurgery and Psychiatry 47:927-935.

Courtheoux P, Theron J, Serlon JM, et al. 1986 In situ fibrinolysis in supra-aortic main vessels. A preliminary study. Neuroradiology 13:111-124.

DAROLLES M 1875 Ramolissement de la protubérance: thrombose du tronc basilaire. Le Progrès Médicale 3:629-639.

DEHAENE I, MARTIN JJ 1976 Locked-in syndrome: a clinico-pathological study of two cases. European Neurology 14:81-89.

DEHAENE I, Dow R 1982 A mesencephalic locked-in syndrome. fournal of Neurology 227:255259.

Dehaene I, Dom R, Martin JJ 1984 Le syndrome 'locked-in'. Etude clinique de dix cas. Acta Neurologica Belgica 84:12-20.

Delcour C, Mouchette R, Desoignies J, Reznik M 1982 Confrontations anatomo-cliniques. Le locked-in syndrome. Revue Médicale de Liège 37:465-468.

Delpuech F, Habib M, TAFani B, et al. 1981 Le 'locked-in syndrome'. A propos de trois observations dont deux anatomocliniques. Oto-Neuro-Ophtalmologie 53: 215-224.

EROKHINA LG, GUBSKIOI LV, KHALATOV VS 1986 Locked-in syndrome in vascular pathology of the brain. Zhurnal Nevropatologii Psikhiatrii 86:1284-1290.

FELDMAN MH 1971 Physiological observations in a chronic case of 'locked-in' syndrome. Neurology 21:459-477.

FisHer CM 1964 Ocular bobbing. Archives of Neurology 11:543-546.

FISHER CM 1967 Some neuro-ophtalmological observations. Fournal of Neurology, Neurosurgery and Psychiatry 30:383-392.

Gilroy J, LynN GE, Tistow GE, Pellerin RJ 1977 Auditory evoked brainstem potentials in a case of 'locked-in' syndrome. Archives of Neurology 34:492-495.

Girard PF, Gerest F, Tommasi M, Rouves L 1962 Ramolissement géant du pied de la protubérance. Modifications structurales des olives bulbaires. Tableau clinique voisin du mutisme akinétique de Cairns. Lyon Médical 14:877-892.

Golden GS, LeedS N, KREMENitzer MW, Russman BS 1976 The 'locked-in' syndrome in children. Fournal of Pediatrics 89:596-598.

Gouras P 1985 Oculomotor system. In: Kandel E, Schwartz JH Principals of Neural Science, Elsevier, New York, pp. 571-583.

Haig AJ, Katz RT, SAGHAL V 1987 Mortality and complications of the locked-in syndrome. Archives of Physical Medicine and Rehabilitation 68:24-27.

HAWkES CH 1974 'Locked-in' syndrome: report of seven cases. British Medical fournal 4:379382.

Henze Th, Boeer A, Tebbe U, Romatowski J 1987 Lysis of basilar artery occlusion with tissue plasminogen activator. Lancet 12:1391.

KARP JS, HURTIG HI 1974 'Locked-in' state with bilateral midbrain infarcts. Archives of Neurology 30:176-178.

KEANE JR 1986 Locked-in syndrome after head and neck trauma. Neurology 36:1647-1649.

KELLY P 1985 Cranial nerve nuclei, the reticular formation, and biogenic amine-containing neurons. In: KANDEL ER, Schwartz JH, Principles of Neural Science, Elsevier, New York, pp. 539-561.

Kotagal S, Rolfe U, Schwartz KB, Escober W 1984 'Locked-in' state following Reye's syndrome. Annals of Neurology 15:599-601.

MARKAND ON, DYKEN ML 1976 Sleep abnormalities in patients with brainstem lesions. Neurology 26:769-776.

Masson M, Prier S, Henin D et al. 1978 Sémiologie neuro-ophtalmologique des lésions protubérantielles. Oto-Neuro-Ophtalmologie 50:107-117.

MCCuSKer EA, Rudick RA, HoNCH GW, GRIGGS RC 1982 Recovery from the locked-in syndrome. Archives of Neurology 39:17-21.

Meienberg O, Mumenthaler M, KarbowSKi K 1979 Quadriparesis and nuclear oculomotor palsy with total bilateral ptosis mimicking coma. A mesencephalic 'locked-in syndrome'? Archives of Neurology 36:708-710.

Nemeth G, Hegedus K, Molnar L 1986 Akinetic mutism and locked-in syndrome: the functional-anatomical basis for their differentiation. Functional Neurology 1:128-139.

NoEl P, DESMEDT JE 1975 Somatosensory cerebral evoked potentials after vascular lesions of the brain-stem and diencephalon. Brain 98:113-128.

NoRdgren RE, MARKesbery WR, Fukuda K, ReEves AG 1971 Seven cases of cerebromedullospinal disconnection: the 'locked-in' syndrome. Neurology 21:1140-1148.

ORENSTEIN M 1987 Locked-in syndrome post-traumatique d'installation retardée. Thèse Médicale. 166:81.

Patterson JR, Grabois M 1986 Locked-in syndrome: a review of 139 cases. Stroke 17:758-764. 
PeARCE JMS 1987 The locked-in syndrome. British Medical fournal 294:198-199.

Pierrot-Deseilligny 1985 Circuits oculomoteurs centraux. Revue Neurologique 141:349-370.

Plum F, Posner JB 1966 The diagnosis of stupor and coma. F. A. Davis Company, Philadelphia, pp. 92-93.

Popova JM, Pirogov VN 1986 Thrombolytic therapy with streptodekase in ischemic strokes. Zhurnal Nevropatologii I Psikhiatrii 86:1777-1782.

Prier S, Larmande P, Henin D, et al. 1982 Le syndrome un et demi de Fisher. Association d'une paralysie de la latéralité et d'une ophtalmoplégie internucléaire antérieur. Etude de 5 cas. fournal Français Ophtalmologie 5:49-53.

REZNIK M 1983 Neuropathology in seven cases of locked-in syndrome. Fournal of the Neurological Sciences 60:67-78.

ROBERT H 1980 Les syndromes médians du tronc cérébral. Données polygraphiques. Potentiels évoqués somesthésiques et auditifs. Thèse Médicale 338:109.

SeAles DM, TORKELson RD, Shuman RM 1981 Abnormal brainstem auditory evoked potentials and neuropathology in 'locked-in' syndrome. Neurology 31:893-896.

StOCKaRd JJ, Rossiter VS, Wiederhol T WC, Kobayashi RM 1976 Brain stem auditory-evoked responses in suspected central pontine myelinolysis. Archives of Neurology 33:726-728.

TAMURA K, KaraCAN I, WILliams RL, MAYER JS 1983 Disturbances of the sleep-waking cycle in patients with vascular brain stem lesions. Clinical Electroencephalography 14:35-46.

VIRGILE RS 1984 Locked-in syndrome. Case and literature review. Clinical Neurology and Neurosurgery 86:275-279. 